Disponível em

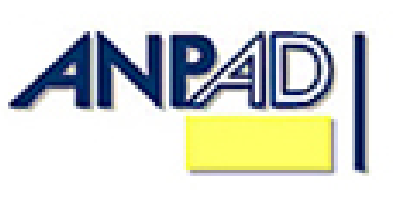

http://www.anpad.org.br/rac

RAC, Rio de Janeiro, v. 18, n. 6,

pp. 892-899, Nov./Dez. 2014

http://dx.doi.org/10.1590/1982-7849rac201412441

$($ (c) EY-No

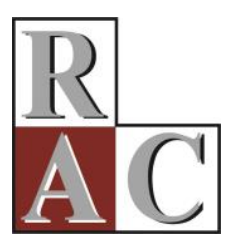

Documentos e Debates:

\title{
Réplica - Empreendedores: Reflexões sobre Concepções Históricas e Contemporâneas
}

\author{
Entrepreneurs: Reflections on Historical and Contemporary Concepts
}

Hilka Pelizza Vier Machado

E-mail: hilkavier@yahoo.com

Universidade Estadual de Maringá - PPA/UEM Av. Colombo, 5790, 87020-900, Maringá, PR, Brasil.

Vânia Maria Jorge Nassif E-mail: vania.nassif@gmail.com Universidade Nove de Julho - PMDA/MPA/GE/UNINOVE Av. Francisco Matarazzo, 612, Prédio C, Água Branca, 05001-100, São Paulo, SP, Brasil. 


\section{Introdução}

O empreendedorismo é um campo de pesquisa em construção, sendo o empreendedor ou os empreendedores uma das dimensões de análise do fenômeno. Gartner (1985) salienta que o empreendedorismo pode ser explicado por meio de quatro dimensões, as quais determinam a criação de novos negócios, são elas: o indivíduo, o processo, a organização e o ambiente. Também na visão processual, que considera o empreendedorismo como um resultado de diversas fases que têm início com a ideia do negócio (Baron \& Shane, 2011), o empreendedor está presente, pois é ele quem direciona todas as etapas do processo.

No entanto o percurso epistemológico do campo não negligencia a importância dos empreendedores para a compreensão do fenômeno, porém evidencia, cada vez mais, que eles não agem isoladamente. Esse direcionamento foi determinado a partir do ano 2000, com a publicação de Shane e Venkataraman na Academy of Management Review, a qual apresentou a abordagem do nexo entre indivíduos e oportunidades. Shane (2012) discute a importância que a referida premissa teve, ao longo da última década, e refletida, notadamente, em diversas contribuições teóricas posteriores sobre identificação e construção de oportunidades por indivíduos, de maneira que a "introdução do conceito de oportunidades mudou o foco do campo de empreendedorismo ao longo dos dez últimos anos” (p. 16).

Ainda que as abordagens sobre oportunidades venham consolidando um novo momento na evolução do campo, estudos com enfoques em empreendedores continuam relevantes. Mas é preciso levar em consideração a dimensão temporal na medida em que ela mostra como o empreendedor é fruto da sua época e do meio, pois é em dado contexto de tempo e de espaço que se pode compreender a relação dialógica entre indivíduos e criação de valor (Bruyat \& Julien, 2001; Julien, 2010).

Este ensaio teórico é uma resposta ao convite formulado pelo editor desta revista para uma réplica ao artigo intitulado Empreendedor: Origens, Concepções Teóricas, Dispersão e Integração. Por meio de breve síntese sobre concepções históricas e contemporâneas de empreendedores, apresenta-se um olhar complementar com o intuito de ampliar as reflexões atinentes à natureza e identidade de empreendedores no decurso da história.

\section{Empreendedores e concepções históricas}

As primeiras referências aos empreendedores são atribuídas ao grupo de fisiocratas liderado por François Quesnay (1694-1774), para o qual o capital era proveniente da terra. Quesnay compartilhava com Cantillon a visão econômica (Hébert \& Link, 2006). Cantillon (1680-1734) fazia parte do grupo dos fisiocratas e compreendia os empreendedores como indivíduos que exerciam papel arbitrário no equilíbrio entre oferta e demanda, procurando introduzir mudanças no mercado para obter lucro (Landström \& Lohrke, 2010). Cantillon distinguiu três classes de agentes econômicos: os proprietários de terras, que eram independentes financeiramente; os empreendedores, que se engajavam na realização de trocas no mercado, assumindo riscos para obter lucros e, por fim, os assalariados. Ele considerava o empreendedor como alguém dono de seu próprio trabalho, que não precisava de capital para se estabelecer, incluindo nesta categoria os artistas, comerciantes, cientistas e até mesmo mendigos e ladrões (Hébert \& Link, 2006). Posteriormente, Jean Baptiste Say (1767-1832) salientaria o papel de coordenação entre produção e distribuição, exercido por empreendedores. Para Say, o empreendedor necessitaria encontrar um mercado e suas ações precisariam ser direcionadas para "criar valor ou utilidade" (Hébert \& Link, 2006, p. 288).

A noção de empreendedor no pensamento inglês foi introduzida por Adam Smith, que, em 1776, publicou a obra sobre a riqueza das nações. Em Adam Smith (1723-1790), identificam-se as noções do empreendedor como trabalhador superior, ou, ainda, como especulador e acumulador de riquezas (Hébert \& Link, 2006; Rodríguez \& Jiménez, 2005; Zen \& Fracasso, 2008). Para Smith, a inovação é produto da divisão do trabalho, que, por sua vez, é dependente da extensão do mercado (Hébert \& Link, 2006). 
Dessas contribuições pioneiras sobre o papel dos empreendedores da era econômica, integram-se pensamentos de economistas clássicos alemães, tais como Hans Von Mangoldt (1824-1858), Friedrich Hermann (1795-1868) e J. H. Von Thünen (1783-1850), sendo que este descrevia o empreendedor como inovador e alguém que assumia riscos (Hébert \& Link, 2006). Hans Von Mangoldt, professor universitário em Gottingen e Freiburg, caracterizava o empreendedor como inovador e, ainda, como um supervisor, atribuindo-lhe habilidades de escolha de técnicas, de alocação dos fatores de produção e de venda dos produtos (Hébert \& Link, 2006; Rodríguez \& Jiménez, 2005).

Além da era econômica, Rodríguez e Jiménez (2005) distinguem outro período de estudos, constituído pelos neoclássicos, que é representado pelos pensamentos de autores como Carl Menger (1840-1921), Max Weber (1864-1920), Alfred Marshall (1842-1924), Keynes (1883-1946) e Knight (1885-1972). Entre estes, alguns nomes integraram a escola econômica austríaca, que enfatizava a importância da subjetividade na teoria econômica, cujo pensamento foi introduzido por Carl Menger, por meio da obra Princípios da Economia, em 1871. Para Menger, a atividade do empreendedor incluía a busca de informações econômicas, assim como a transformação de materiais e a supervisão da produção (Hébert \& Link, 2006) ${ }^{(1)}$. Mas o líder da escola austríaca foi Ludwig von Mises (1881-1973), cujos estudos apresentaram a noção de independência dos indivíduos e da ação humana como capaz de fazer uso de oportunidades. Von Mises influenciou o pensamento de Friederich Von Hayek (18991992), o qual enfatizou a importância do conhecimento e a dispersão do conhecimento na sociedade, o que favoreceria o constante processo de descobertas (Casson, 2003; Landström \& Lohrke, 2010).

Após a Guerra Civil Americana, em 1865, os Estados Unidos iniciam um período de reconstrução que resultou no reconhecimento do papel de intelectuais e no envio de alguns deles para estudar na Europa. Ao mesmo tempo, Amasa Walker (1799-1875) defende a importância do empreendedor para a criação de riqueza econômica (Hébert \& Link, 2006). Enquanto, para neoclássicos como Alfred Marshall e Keynes, o empreendedor é um trabalhador superior (Rodríguez \& Jiménez, 2005), para Frank Knight (1885-1972), o empreendedor é o indivíduo que assume não apenas riscos, mas incertezas, sendo que as incertezas são resultantes da capacidade humana finita de fazer julgamentos (Radow, 2010).

No período compreendido entre 1830 e 1910, as escolas econômicas britânicas e austríacas dominaram a teoria econômica, não obstante a contribuição do francês León Walras (1834-1910), que considerava o empreendedor como um intermediário entre a produção e o consumo. As ideias desses economistas enfatizavam o empreendedorismo como motor do desenvolvimento econômico, incluindose as discussões sobre a noção de empresário (Charry, 2010).

Após esse período, os estudos no campo do empreendedorismo foram influenciados por estudos sociológicos, como os de Max Weber (1864-1920) e Werner Sombart (1863-1941). As noções de empresário, para Max Weber, que era empresário tradicional e capitalista, são representadas pela ética em conjunto com a busca de riqueza, que valorizava o trabalho e a busca de rendimentos e lucros. Sombart apresentou originalmente as ideias sobre o empreendedor como agente da destruição criativa (Landström \& Lohrke, 2010).

O caráter inovador do empreendedor é retomado por Schumpeter (1883-1950), considerando, então, o empreendedor como um destruidor criativo do mercado, que provocaria desequilíbrio (Rodríguez \& Jiménez, 2005; Zen \& Fracasso, 2008). Para Schumpeter, o empreendedor exerceria papel de liderança, com imaginação criativa. Ele postulou a ocorrência de "inovação e ondas de adaptação" (Hébert \& Link, 2006, p. 361), decorrentes da atuação empreendedora. Enquanto, para Schumpeter (1939), o empreendedor favorece o desequilíbrio de mercado, para Israel Kirzner (1973), o empreendedor é um agente de equilíbrio, pelo papel que exerce na coordenação do mercado e pelo alerta às mudanças. $\mathrm{O}$ empreendedor é promotor de ajustes e provocador de equilíbrio nos mercados. Por meio do alerta, o empreendedor demonstra elevada percepção, reconhecendo oportunidades de negócios. Ele se engaja em um processo sistemático de busca, o que o torna alerta às incertezas e mudanças e, com isso, a visão o distinguiria dos demais indivíduos (Douhan, Eliasson, \& Henrekson, 2007; Hébert \& Link, 2006). 
Em 1932, Joseph Schumpeter começou a lecionar na Harvard University e, em 1946, foi criado o centro de pesquisas em empreendedorismo naquela universidade, por Arthur Cole. Posteriormente, em 1947, ocorreu a oferta do primeiro curso em empreendedorismo pela Universidade de Harvard (Hébert \& Link, 2006). Com isso, outras áreas influenciaram a compreensão das identidades dos empreendedores, como, por exemplo, a sociologia e a psicologia. Sociólogos como Talcott Parsons filiaram-se ao centro de pesquisa e deram início a pesquisas que procuravam compreender como contextos históricos e estruturas sociais influenciavam os empreendedores. Ademais, estudos no campo da Sociologia contribuíram para identificar a importância do papel relacional e das redes sociais na ação do empreendedor (Granovetter, 1973), bem como para compreender o empreendedor como produto da cultura.

Entre as abordagens da psicologia que exerceram influência nos debates, menciona-se a de David McClelland, cuja publicação, em 1961, salientava a importância do desejo de realização como traço do comportamento de empreendedores (Landström \& Lohrke, 2010).

\section{Empreendedores, concepções contemporâneas}

Para Landström e Lohrke (2010), a partir de 1970, as pesquisas no campo do empreendedorismo ingressaram na era gerencial. Esta se caracteriza pela criação de organizações profissionais, como, por exemplo, o International Council of Small Business e o Small Business Center, este nos Estados Unidos; como também pela introdução de diversas fontes de publicações científicas específicas, com abrangência internacional.

Publicações de outra natureza são tidas como relevantes para a construção do campo científico, como o Panel Studies of Entrepreneurial Dynamics, da Universidade de Michigan, em 2005 (Reynolds \& Curtin, 2008), e, em 1997, a criação do relatório Global Entrepreneurship Monitor (GEM), pela Babson College e pela London Business School. Nesse período, o empreendedorismo passou a ser discutido como um fenômeno complexo e heterogêneo (Davidsson, 2008) e, como salienta Hernandez (1999, p. 19), “o empreendedor é o iniciador de um processo complexo" que, para Frese (2009), requer a persistência.

O empreendedor caracteriza-se como alguém que identifica oportunidades (Shane \& Venkataraman, 2000). É o acúmulo de conhecimentos e a motivação para a criação de valor que capacita os indivíduos a explorarem oportunidades e a tornarem-se empreendedores (McMullen \& Shepherd, 2006). Habilidades e motivações estão associadas com a criação de valores (Julien, 2010).

Para concepções contemporâneas, o empreendedor apresenta-se como um agente relacional, atuando em networks e em redes sociais (Julien, 2010; Sarasvathy, 2008). Ele é um agente social ativo, que cria valor (Bruyat \& Julien, 2001), identifica e explora oportunidades (Shane \& Venkataraman, 2000), constrói artefatos ou mercados (Sarasvathy, 2008).

Empreendedores, como sujeitos contemporâneos, não estão apenas alertas ao ambiente e às mudanças, como Kirzner (2009) mencionou, mas eles também constroem oportunidades ou criam artefatos, por meio de seus recursos pessoais e da interação com outras pessoas, com as quais eles fazem acordos e, com isso, transformam os seus recursos em novos meios e objetivos (Sarasvathy, 2008). Os empreendedores não só reconhecem e descobrem, mas também criam oportunidades (Sarasvathy, Dew, Velamuri, \& Venkataraman, 2002). Eles desenvolvem oportunidades, com base em redes de contatos sociais e em conhecimentos e experiências prévias que possuem (Ardichvili, Cardozo, \& Ray, 2003). As interações sociais favorecem o poder de agência dos empreendedores (Sarason, Dean, \& Dillard, 2006).

O conhecimento, a criatividade e a habilidade relacional e, não necessariamente o acúmulo de recursos físicos, distinguem os empreendedores. Para abordagens contemporâneas, também, a penúria ou escassez de recursos, pode resultar em criação de valor ou em crescimento, como no caso da bricolagem (Backer \& Nelson, 2005; Fisher, 2012). Isso pode ser observado na figura dos empreendedores sociais que se ampliam na contemporaneidade (Smith \& Woodworth, 2012). 
A diversidade consiste em um dos aspectos importantes para compreensões contemporâneas de empreendedores. Além da participação de diferentes atores, como o caso dos empreendedores sociais, a diversidade pode ser considerada sob a ótica de diferentes tipos de empreendedores, salienta Julien:

O empreendedor de reprodução, que muda pouco e cria menos valor. Ele se contenta em reproduzir o que já viu em outro lugar ou o que fazia na empresa onde trabalhava, assumindo novas responsabilidades. Sua gestão é tradicional ... suas responsabilidades e a evolução do ambiente podem forçá-lo a mudar, mas essa evolução é reativa. O empreendedor de imitação, que não cria muito valor novo, mas é influenciado por essa criação ... muda psicologicamente quando domina o medo do desconhecido para assumir novas responsabilidades sobre seu destino, levando-o a constituir redes, criar estratégias e aperfeiçoar o valor do que oferece. $\mathrm{O}$ empreendedor de valorização, que desenvolve rotinas de gestão e garante a fidelidade de seus clientes, procede a importantes mudanças, adota estratégias mais ativas. E, o mais raro, ainda que seja o mais citado, são os empreendedores de aventura, que criam empresas inovadoras, mas de risco. O valor que cria pode ser crucial, podendo formar um novo setor. (Julien, 2010, pp. 119120).

Nesse sentido, a inovação continua sendo considerada um traço importante para categorizar empreendedores, porém em diferentes níveis de criação de valor. Além deste comportamento inovador, os empreendedores continuam sendo identificados como indivíduos que enfrentam riscos, agem na incerteza e precisam de criatividade para explorar ou construir oportunidades (Janney \& Dess, 2006; McMullen \& Shepherd, 2006). Hébert e Link (2006) acrescentam também o papel do empreendedor como o de "alocador de recursos" (p. 392).

Sucintamente, abordagens contemporâneas englobam compreensões multidisciplinares, atribuindo ao empreendedor o papel de ator relacional, capaz de construir ou desenvolver oportunidades de negócios, utilizando-se de recursos pessoais e sociais. Eles agem na incerteza, munidos de habilidades e de motivações, criando diferentes formas de negócios, desde a imitação até a inovação radical.

Ademais, como empreendedores estão inseridos em ambientes socioculturais, identidades plurais podem ser observadas, como, por exemplo, o mais liberal no contexto norte-americano, o corporativista à francesa, o tipo comunitário africano ou até o intermediário entre as grandes empresas e o mercado presente na estrutura hierárquica asiática, formada por milhares de pequenas empresas (Julien, 2010). Contudo poucos estudos exploraram essas dimensões plurais, evidenciando que a compreensão do papel e da identidade de empreendedores não se exauriram no campo.

\section{Considerações Finais}

Compreensões históricas do empreendedor, objeto de estudos anteriores (Costa, Barros, \& Carvalho, 2011), procuram identificar a influência do tempo, da história e de outras áreas do conhecimento nas conformações de identidades de empreendedores.

A revisão da literatura, apresentada no ensaio teórico em foco, trouxe alguns recortes da história que mostraram a contribuição de estudos da área econômica e que constituíram a gênese do pensar o empreendedor no campo do empreendedorismo, tal como o que foi realizado no artigo que deu origem a este ensaio. Posteriormente, por um lado, com as contribuições advindas de estudiosos da área social, a dimensão do papel empreendedor ampliou-se, produzindo maior complexidade, mas, por outro lado, apresentou uma identidade social de empreendedores, assim, evidenciando compreensões distintas dos empreendedores, e não apenas individualmente do empreendedor. Tal percurso epistemológico revelou mais uma integração do que uma fragmentação na medida em que elementos contidos nas abordagens históricas de empreendedor podem ser encontrados em abordagens contemporâneas. 
Entretanto vale ressaltar que compreensões da história são sempre limitadas, quer pela impossibilidade de avaliação atual minuciosa sobre eventos passados, na medida em que eles são avaliados como fatos contados, quer pela simplificação necessária para abordagens desta natureza.

Por fim, inserida no campo das ciências sociais, a compreensão do papel empreendedor requer pesquisas adicionais, como apontam Brush, Manolova e Edelman (2008) e Davidsson (2008), o que torna importante continuar construindo a integração com outras áreas do conhecimento, como sugere Zahra (2005).

\section{Nota}

\footnotetext{
${ }^{1}$ Representantes da escola austríaca do pensamento econômico são considerados como precursores da era econômica para Landström e Lohrke (2010).
}

\section{Referências}

Ardichvili, A., Cardozo, R., \& Ray, S. (2003). A theory of entrepreneurial opportunity identification and development. Journal of Business Venturing, 18(1), 105-123. doi: 10.1016/S08839026(01)00068-4

Backer, T., \& Nelson, R. E. (2005). Creating something from nothing: resource construction through entrepreneurial bricolage. Administrative Science Quarterly, 50(3), 329-366. doi: 10.2189/asqu.2005.50.3.329

Baron, R., \& Shane, S. (2011). Empreendedorismo - uma visão do processo. São Paulo: Thomson.

Brush, C. G., Manolova, T. S., \& Edelman, L. F. (2008). Separated by common language? Entrepreneurship research across the Atlantic. Entrepreneurship Theory and Practice, 32(2), 249266. doi: $10.1111 / \mathrm{j} .1540-6520.2007 .00225 . \mathrm{x}$

Bruyat, C., \& Julien, P.-A. (2001). Defining the field of research in entrepreneurship. Journal of Business Venturing, 16(2), 165-180. doi: 10.1016/S0883-9026(99)00043-9

Casson, M. (2003). The entrepreneur - an economic theory (2nd ed.). Northampton: Edward Elgar.

Charry, G. P. (2010). Empresariabilidad y empresa: una aproximación desde la escuela Austríaca. Estudios Gerenciales, 26(115), 161-178.

Costa, A. M. da, Barros, D. F., \& Carvalho, J. L. F. (2011). A dimensão histórica dos discursos acerca do empreendedor e do empreendedorismo. Revista de Administração Contemporânea, 15(2), 179-197. Recuperado de http://www.scielo.br/pdf/rac/v15n2/v15n2a02.pdf. doi: 10.1590/S141565552011000200002

Davidsson, P. (2008). Looking back at 20 years of entrepreneurship research: what did we learn? In H. Landström, H. Crijns, E. Laveren, \& D. Smallbone (Eds.), Entrepreneurship sustainable growth and performance (pp. 13-26). Northampton: Edward Elgar.

Douhan, R., Eliasson, G., \& Henrekson, M. (2007). Israel M. Kirzner: an outstanding Austrian contributor to the economics of entrepreneurship. Small Business Economics, 29(1/2), 213-223. doi: 10.1007/s11187-006-9041-y 
Fisher, G. (2012). Effectuation, causation and bricolage: a behavioral comparison of emerging theories in entrepreneurship research. Entrepreneurship Theory and Practice, 36(5), 1019-1050. doi: 10.1111/j.1540-6520.2012.00537.x

Frese, M. (2009). Toward a psychology of entrepreneurship: an action theory perspective. Foundations and Trends in Entrepreneurship, 15(6), 437-496. doi: 10.1561/0300000028

Gartner, W. B. (1985). A conceptual framework for describing the phenomenon of new venture creation. The Academy of Management Review, 10(4), 696-706. doi: 10.5465/AMR.1985.4279094

Granovetter, M. S. (1973). The strength of weak ties. American Journal of Sociology, 78(6), 1360-1380.

Hébert, R. F., \& Link, A. N. (2006). Historical perspectives on the entrepreneur. Foundations and Trends in Entrepreneurship, 2(4), 261-408. doi: 10.1561/0300000008

Hernandez, É. M. (1999). Le processus entrepreneurial: vers umn modèle stratégique d' entrepreneuriat. Paris: L' Harmattan.

Janney, J. J., \& Dess, G. G. (2006). The risk concept for entrepreneurs reconsidered: new challenges to the conventional wisdom. Journal of Business Venturing, 21(3), 385-400. doi: 10.1016/j.jbusvent.2005.06.003

Julien, P. A. (2010). Empreendedorismo regional e economia do conhecimento. São Paulo: Saraiva.

Kirzner, I. M. (1973). Competition and entrepreneurship. Chicago: University of Chicago Press.

Kirzner, I. M. (2009). The alert and creative entrepreneur: a clarification. Small Business Economics, 32(2), 145-152. doi: 10.1007/s11187-008-9153-7

Landström, H., \& Lohrke, F. (2010). Historical foundations of entrepreneurship research. Great Britain: Edward Elgar Publishing.

McMullen, J. S., \& Shepherd, D. A. (2006). Entrepreneurial action and the role of uncertainty in the theory of the entrepreneur. Academy of Management Review, 31(1), 132-152. doi: 10.5465/AMR.2006.19379628

Radow, T. (2010). Risk, uncertainty and prophet: the psychological insights of Frank H. Knight. Judgment and Decision Making, 5(6), 458-466.

Reynolds, P., \& Curtin, R. (2008). Business creation in the United States: panel studies of entrepreneurial dynamics. Foundations and Training in Entrepreneurship, 4(3), 155-307. doi: $10.1561 / 0300000022$

Rodríguez, C., \& Jiménez, M. (2005). Empreendedorismo, acción gubernamental y academia. Revisión de la literatura. Innovar, 15(26), 73-89.

Sarason, Y., Dean, T., \& Dillard, J. (2006). Entrepreneurship as the nexus of individual and opportunity: a restructuration view. Journal of Business Venturing, 21(3), 286-305.

Sarasvathy, S. D. (2008). Effectuation elements of entrepreneurial expertise. Great Britain: Edward Elgar Publishing.

Sarasvathy, S. D., Dew, N., Velamuri, S. R., \& Venkataraman, S. (2002, August 16). A testable typology of entrepreneurial opportunity: extension of Shane \& Venkataraman (2000) (First Draft). Academy of Management Review.

Schumpeter, J. A. (1939). Business cycles. A theoretical, historical and statistical analysis of the capitalist process. New York Toronto London: McGraw-Hill Book Company. 
Shane, S. (2012). Reflections on the 2010 AMR decade award: delivering on the promise of entrepreneurship as a field of research. Academy of Management Review, 37(1), 10-20. doi: 10.5465/amr.2011.0078

Shane, S., \& Venkataraman, S. (2000). The promise of entrepreneurship as a field of research. Academy of Management Review, 25(1), 217-226. doi: 10.5465/AMR.2000.2791611

Smith, I. H., \& Woodworth, W. P. (2012). Developing social entrepreneurs and social innovators: a social identity and self-efficacy approach. Academy of Management Learning \& Education, 11(3), 390-407. doi:10.5465/amle.2011.0016

Zahra, S. A. (2005). Entrepreneurship and disciplinary scholarship: return to the fountainhead. Interdisciplinary Perspectives. In S. A. Alvarez, R. Agarwal, \& O. Sorenson (Eds.), Handbook of entrepreneurship research. interdisciplinary perspectives (pp. 253-268). New York: Springer.

Zen, A. C., \& Fracasso, E. M. (2008). Quem é o empreendedor: as implicações de três revoluções tecnológicas na construção do termo empreendedor. Revista de Administração Mackenzie, 9(8), 135-150. doi: 10.1590/S1678-69712008000800008 